RECENSIONES DE TESIS 


\title{
AUDITORÍAS DE GESTIÓN: UNA TAREA PENDIENTE EN EL TRIBUNAL DE CUENTAS DE LA PROVINCIA DE SANTA FE
}

\author{
Tesista \\ María Agustina López
}

Director de tesis

Bruno Ariel Rezzoagli

En la última década del Siglo XX emerge la doctrina del New Public Management (o Nueva Gestión Pública) que se traduce en la proposición de ciertos postulados básicos que pretenden la «reinvención del gobierno». Este nuevo enfoque, que traslada el modelo gerencial privado al sector público, supone la búsqueda de mayor efectividad en la acción estatal, convirtiendo el rol del Estado en "catalizador" de las acciones previstas. En esencia, dentro de sus postulados básicos se destaca la gestión pública basada en objetivos, orientada hacia la consecución y la calidad de los resultados, y dirigida hacia los clientes-ciudadanos, incrementando la participación ciudadana directa en la gestión pública (Fernández Llera, 2010).

Asimismo, reciben un fuerte impulso las cuestiones relativas a la transparencia dentro de la administración pública y la rendición de cuentas —accountability - (Oszlack, 1999). La noción convencional de la accountability podría ser entendida como "rendición de cuentas", en el sentido a la creación de mecanismos institucionales que permitan el control y la supervisión social como práctica 167 institucionalizada (Barzelay, 1998). Según Cunill Grau (2000), la accountability no sólo implica controlar los resultados de la acción administrativa ("lo que se hace») sino incidir acerca de lo que se "decide hacer", teniendo en cuenta las consecuencias para la sociedad.

Bajo este marco, el control público y la auditoría se constituyen en pilares fundamentales, a los efectos de garantizar a la ciudadanía el adecuado manejo de los fondos públicos. Tal es así que surge la necesidad de un cambio en los enfoques de control externo, desde el tradicional control legal o financiero hacia un control que abarque diversos aspectos de la gestión gubernamental.

En este contexto, se evidencia la necesidad de realizar auditorías de gestión o del rendimiento que examinen, además de los aspectos financieros y de legalidad, los de economía, eficiencia y eficacia. 
La auditoría de gestión es un examen independiente de la eficiencia, la eficacia y la economía de las actividades, los programas o los organismos de la Administración pública, con el propósito de llevar a cabo mejoras (INTOSAI, ISSAI 3000, 2003). Involucra el examen de planes, programas, proyectos y operaciones de una organización o entidad pública, a fin de medir e informar sobre el logro de los objetivos previstos, la utilización de los recursos públicos en forma económica y eficiente y la fidelidad con que los responsables dan cumplimiento a las normas del caso. Se integra además con la medición de impacto en términos de calidad y satisfacción del usuario (Pizzuto, 2006). Ciertamente, este tipo de auditoría pretende determinar si los programas públicos se gestionan de la mejor manera, respetando los principios de economía, eficacia, eficiencia y cuidado del medio ambiente (INTOSAI, 2013) ${ }^{1}$.

Ahora bien, a pesar de que la auditoría de gestión ha sido incorporada formalmente tanto en la legislación de administración financiera nacional como en la mayoría de las subnacionales, su aplicación no ha sido concretada en gran parte de los órganos de control externo de nuestro país, más allá de los controles efectuados en el marco de la Red Federal de Control Público (SIGEN) ${ }^{2}$.

Esta situación se sustenta básicamente en la concepción tradicional de estos órganos de control, creados originalmente con funciones de control formal-legal y de regularidad (financiero-contable). Lo cierto es que si bien a partir del año 2006, como consecuencia del dictado de la Ley 12.510, se confiere al Tribunal de Cuentas de la Provincia de Santa $\mathrm{Fe}$ (TCPSF) la facultad de realizar auditorías de gestión, en la práctica es una dimensión poco desarrollada y explorada. Ante esta realidad nos preguntamos ¿Es posible que el Tribunal de Cuentas realice auditorías de gestión?
¿Cuáles son las condiciones que deberían darse? Y, siguiendo este orden de ideas, inferimos que existen ciertos condicionantes, tanto internos como externos, que dificultan su concreción, al menos en el corto plazo.

Por lo expuesto, el objetivo general de la presente investigación consiste en determinar las condiciones necesarias para el desarrollo de auditorías de gestión en el ámbito del TCPSF, para optimizar el control en la utilización de los fondos públicos provinciales. A los efectos de alcanzar este objetivo general, nos planteamos los siguientes objetivos específicos: considerar las experiencias de diversos órganos de fiscalización que han incorporado auditorías de gestión a sus planes de acción; analizar el desarrollo de la función de auditoría en el ámbito del TCPSF; examinar la dotación de recursos materiales y humanos y las capacidades técnicas inherentes al organismo; investigar la coordinación y cooperación existentes entre los órganos de control interno y externo a nivel provincial; $y$ finalmente, analizar si los organismos del sector público provincial sujetos al control del Tribunal son capaces de proporcionar la información de tal forma que permita la realización de este tipo de auditorías.

\section{METODOLOGÍA DE TRABAJO UTILIZADA}

El trabajo se desenrolló siguiendo un estudio no experimental descriptivo de la temática de interés, teniendo en cuenta la situación actual del TCPSF con relación a la problemática planteada. A los efectos mencionados, se utilizó la estrategia cualitativa, sobre la base de un análisis teórico sustentado en técnicas de investigación documental, junto a un análisis práctico basado en la observación directa de los procedimientos de auditoría vigentes en el TCPSF, desde una visión comparativa con otros organismos de fiscalización.

Las actividades para dar respuesta a la situación problemática, se abordaron en tres 
momentos. En un primer momento, elaboramos la problematización del objeto de estudio, utilizando como técnicas de recolección de datos el análisis documental y las entrevistas a funcionarios, idóneos e informantes claves. En un segundo momento, desarrollamos un análisis crítico de la problemática, de acuerdo a los objetivos específicos definidos, culminando con un análisis FODA del TCPSF. Por último, construimos una propuesta alternativa, que expone las mejores prácticas para llevar a cabo auditorias de gestión en el Tribunal de Cuentas de la Provincia.

\section{RESULTADOS PRINCIPALES}

Como consecuencia de este trabajo de investigación, determinamos que los condicionantes que dificultan la concreción de auditorías de gestión en el TCPSF son los siguientes:

- La función de auditoría se concentra casi exclusivamente en la realización de auditorías financieras de estados contables, a excepción de aquellas planificadas en el marco de la RFCP pero que conciernen a programas nacionales.

- Los recursos humanos destinados a la realización de auditorías resultan exiguos, tornándose difícil la conformación de equipos interdisciplinarios.

- Si bien se verifica cierta vinculación formal entre los órganos de control interno y externo a nivel provincial, no se ha logrado la coordinación y cooperación prevista por la Ley.

- Se observa cierta renuencia a brindar dicha información por parte de los organismos auditados o bien la misma no reúne las condiciones mínimas requeridas.

- Los sistemas de información de la administración gubernamental continúan enfocados en variables de tipo financiero. La ausencia de objetivos definidos y la falta de creación de indicadores de gestión, dificulta la posibilidad de efectuar comparaciones y obtener resultados de forma oportuna y sencilla.

\section{CONCLUSIONES}

Por consiguiente, de acuerdo al examen del marco normativo y a la experiencia práctica de ciertos organismos de fiscalización analizados, destacamos como mejores prácticas para avanzar hacia la concreción de auditorías de gestión en el TCPSF: formular normas específicas y/o manuales de procedimientos, conformar equipos de profesionales interdisciplinarios, planificar las auditorías, instar al diseño de indicadores de gestión y sensibilizar a la población sobre la importancia de tales auditorias.

En suma, planteamos una propuesta alternativa hacia adentro de la organización, tendiente a facilitar la incorporación de estas auditorías dentro de su campo de actuación. Con ese propósito, consideramos que, en primera medida, su inserción dependerá de una decisión política, para lo cual deberán analizarse las relaciones costo/beneficio y las formas de llevar a cabo este proceso de reforma. Aunque advertimos que actualmente existen condicionantes, creemos que se pueden asumir una serie de actividades que propicien las reformas necesarias y permitan la creación de las condiciones requeridas. En consecuencia, proponemos:

- Modificación de la estructura orgánica a los efectos de incorporar un área específica de auditoría.

- Reconversión de los recursos humanos del organismo, quienes deben adaptarse y capacitarse específicamente en técnicas de auditoría y control de gestión.

- Adecuación de la normativa vigente y creación de guías metodológicas y/o manuales de auditoría propios que contemple un apartado especial sobre auditorias de gestión. 
- Conformación de equipos de trabajo interdisciplinarios, en base a la especificidad y capacidades adquiridas respecto de las funciones de auditoría y control por resultados.

- Fortalecimiento de los vínculos con el Sistema de Control Interno y con las jurisdicciones y entidades que integran el Sector Público Provincial No Financiero.

- Concientización de los auditados y la ciudadanía en general sobre la utilidad de las auditorías de gestión.

\section{NOTAS}

${ }^{1}$ El campo semántico a partir del cual se desarrolla la presente investigación, aborda tanto la doctrina autorizada en la materia como las nociones adoptadas por ciertas Entidades de Fiscalización, como ser la Organización Internacional de Entidades Fiscalizadoras Superiores (INTOSAI), el Tribunal de Cuentas Europeo (TCE), el Tribunal de Cuentas de la Unión de Brasil (TCU), la Auditoría General de la Nación (AGN) y la Sindicatura General de la Nación (SIGEN). ${ }^{2}$ Este emprendimiento organizacional instituido a partir del año 2002, descentraliza la fiscalización de los programas sociales financiados con fondos nacionales en los órganos de control de las provincias y municipios de todo el país.

\section{PARA CITAR ESTE ARTÍCULO:}

López, M.A. (2018). "Recensión de tesis: "Auditorías de gestión: una tarea pendiente en el Tribunal de Cuentas de la Provincia de Santa Fe" ", DAAPGE, año 18, № 30 (ene-jun), 2017, pp. 167-170. Santa $\mathrm{Fe}$, Argentina: UNL. 